\title{
Conceptual design for data flow for a database management system for the sustainable recovery of critical metals from waste electrical and electronic equipment
}

\author{
Peñaherrera F. ${ }^{1,}{ }^{*}$, Reinhardt R. ${ }^{2}$ and Kousaiti A. ${ }^{3}$ \\ ${ }^{1}$ Carl von Ossietzky University of Oldenburg, Germany, Ammerländer Heerstraße 114, 26129 Oldenburg \\ ${ }^{2}$ Polytechnic University of Catalonia (UPC), Spain, PI. Eusebi Güell 6, 08034 Barcelona \\ ${ }^{3}$ Technical University of Crete, Greece, Chania 73100 \\ Received: 11/01/2018, Accepted: 07/05/2018, Available online: 26/09/2018 \\ *to whom all correspondence should be addressed: e-mail: fernando.andres.penaherrera.vaca@uni-oldenburg.de \\ https://doi.org/10.30955/gnj.002581
}

\begin{abstract}
Sustainable recovery of critical metals (CM) from Waste Electrical and Electronic Equipment (WEEE) in the European Union (EU) requires information for detailed analysis, monitoring and decision-making. Related knowledge is currently insufficient or disseminated through the network of stakeholders. This paper assesses the requirements of an adequate Database Management System (DBMS) with participation of different actors involved in the recovery of critical metals and analyses the difficulties and the possibilities found for its implementation. The authors define a conceptual scheme of a DBMS to assess the information requirements and to establish the interactions between different actors of the WEEE supply chain, with the aim of supplying standardized information for management and research. Barriers are studied through a survey to identify obstacles for its elaboration. Limitations for its development are addressed and practical solutions for its elaboration are presented.
\end{abstract}

Keywords: Database, recovery, critical metals, waste electrical and electronic equipment, sustainable recovery.

\section{Introduction}

Due to the finite nature of raw materials stocks, the flow of substances through the various stages of processing, consumption and use should be managed to facilitate optimum reuse and recycling (OJEU, 1993). The production of modern electronics requires the use of scarce and expensive resources (Eurostat, 2016). Waste management is indicated as a key component for sustainable development (OJEU, 1993).

The change in technology and the consumer demand for electrical and electronic equipment (EEE), has accelerated in recent years, making the electronics industry the fastest growing and largest economic sector around the world (Puckett et al., 2002). The uncontrolled rapid uptake of information technology (IT) in combination with continuous re-designs and new technologies has created a culture of use-and-throw. The result of this technology driven paradigm is that EEE becomes obsolete at an early stage in their product life cycle, sometimes within only a few months of their release (Khan et al., 2013). The average lifespan of central processing units in computers has decreased from 4-6 years in 1997 to 2 years in 2005 (Babu et al., 2007), which has been reduced even further.

Reliable data on waste production, treatment facilities and management are partial requirements for the implementation of a community legislation and for the evaluation of the waste management (OJEU, 1993). Measures must be taken by actors across the lifecycle of a product to facilitate the preparation for re-use and correct treatment. The whole product lifecycle should be considered to optimize reuse and recovery (EU 7/4/2012, p. 39). For products in the category of Electrical and Electronic Equipment (EEE) and the generated Waste Electrical and Electronic Equipment (WEEE), statistics on their lifecycle are necessary to monitor the achievement of the objectives of the European Union (EU) Directive (EU 7/4/2012, p. 41).

There are existing data sources on WEEE in Europe, such as Eurostat, which provides statistics collected under the Waste Statistics Regulation (Eurostat, 2017), and a database on imported and exported goods. However, limited information on WEEE treatment capacity in the EU28 Member States (MS) is available in the existing databases. Additionally, precise information about the CM content in WEEE is difficult to obtain, a problem increased when looking for the content of critical metals (CM) in the individual components.

The large volumes of $\mathrm{CM}$ in EEE, including rare earth elements, as well their supply risk due to limited sourcing in countries have driven the interest of sourcing these elements from WEEE (Marra et al., 2018). Given the increasing demand for these materials alongside 
geopolitical pressures, the recycling and recovery of $\mathrm{CM}$ from E-waste has been underlined as an opportunity to conserve primary resources, prevent waste production and promote circular economy approaches.

Often the producers have insufficient information on content of specific CM (Bakas, 2014). This indicates lack of data and data accessibility across the distinct stages of the lifecycle (Huisman et al., 2007). Lack of available data and information does not allow for an assessment of the impacts of the EU WEEE Directive. This problem, combined with poor collection rates and the threat of (illegal) exports from Europe to developing countries, such as Ghana, Nigeria or India, creates a risky investment environment for recycling infrastructures (Bakas, 2014).

To increase recycling rates of $\mathrm{CM}$ in WEEE in the $\mathrm{EU}$, improved access to data on CM quantities in different products is necessary (Bakas, 2014). This includes understanding where the metals are in various components, the composition of collected WEEE, and accurate sales figures in the EU. Building such a database (DB) of information is additionally complicated by different national interpretations of the WEEE Directive. Instead of making a product information DB at national level, it seems more relevant to do it at a EU scale (Bakas, 2014). The creation of a centralized Database Management System (DBMS) is presented as a solution to address the mentioned gaps and difficulties. This DBMS will allow input of data from different actors, provide transparency on the calculation and estimation methods, give open access to the results to different actors, and allow the presentation of information to the public. This paper discusses the general requirements of such a DBMS, and the limitations for its implementation.

\section{Information requirements from the EU WEEE directive}

The EU WEEE Directive establishes requirements for information sharing and processing for reporting, to ensure the recycling quotas by MS. Information about the weight of EEE placed on the EU market and the rates of collection, preparation, recovery or recycling and export of WEEE collected is necessary to monitor the achievement of the objectives (EU 7/4/2012).

MS shall ensure that information concerning WEEE that is separately collected is transmitted free of charge, including information by collection and treatment facilities, by distributors, or by other means. Information is to be collected annually on the quantities and categories of EEE placed on the markets, collected through all routes, prepared for reuse, recycled and recovered within the MS, and on separately collected WEEE exported, by weight (EU $7 / 4 / 2012$, p. 49). For calculation of collection rates, a common methodology for the calculation of weight of $E E E$ should be developed (EU 7/4/2012, p. 41).

MS shall ensure cooperation to establish an adequate flow of information, granting access to the relevant documents and information, subject to the provisions of the local data protection law (EU 7/4/2012, p. 50).
Producers and suppliers of EEE in MS shall register and provide all relevant information regarding their activities, and shall provide information about preparation for re-use and treatment of each type of new EEE placed for the first time on market within one year after their placement, to identify the different EEE components and materials, as well as the location of hazardous substances (EU 7/4/2012, p. 49).

\section{Conceptual design of a database management system for WEEE}

A Database (DB) is an integrated collection of logically related records or files consolidated into a common pool which provides data for one or more multiple uses (Halvorsen, 2016). The DBMS is a collection of interrelated data and a set of programs to access those data efficiently (Taneja, 2017). A primary goal of a DBMS is to retrieve information from and to store additional information in the DBMS (Taneja, 2017). Additional functions of a DBMS include: data management and structuring, data manipulation, provision of data security, and concurrent control (Wei-Pang, 2017). A DBMS standard proposed by ANSI SPARK in 1975 is used worldwide and is the agreed upon standard for DBMS. It proposes an architecture layer which decouples external views on data and the implementation view of data (Darbar and Suthar, 2014). Three levels of data description within the DBMS are in the ANSI SPARK model: conceptual, external, and internal level (Figure 1), corresponding to different views of the data (Darbar and Suthar, 2014). Core of the DB architecture is the internal level of schema, which implements all the inner details and defines the intentions of the DBMS (Masood, 2017). The conceptual level contains the definition of all data to be stored as well as rules and information about that structure and type of that data (Masood, 2017).

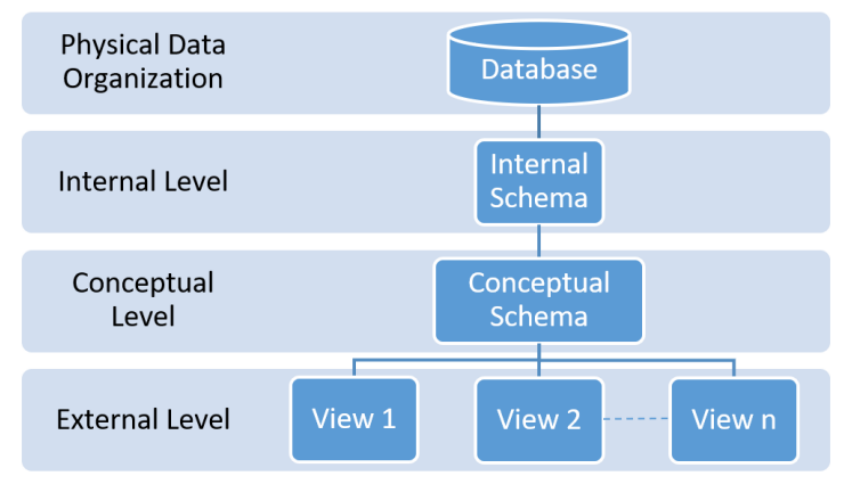

Figure 1. Three Level Architecture of a DBMS Source: Adapted from Masood (2017)

\subsection{Requirements of WEEE data}

The required DB shall capture the dynamics of WEEE flows. A proposal for a relational measurement framework was developed by Baldé (2015), which is based on flows and stocks of EEE and WEEE (Figure 2). Parameters that can be used to gather data for WEEE statistics include: sales of EEE, possession of EEE (in stock), collection of WEEE, noncollected WEEE, exports and imports of WEEE and lifetime 
of products (Baldé, 2015). Data should reflect country totals for the EU-28 nations and might need the application of estimation techniques to obtain the national totals.

The classification system for WEEE statistics should categorise products by similar function, comparable material composition (in terms of hazardous substances and (CM) and related end-of-life attributes. To categorize diverse EEE, UNU-KEYS can be used to collect statistical data on sales. The 54 categories described can be grouped into 10 primary categories, according to the EU WEEE Directive (Baldé, 2015). DB need to comply with certain formats to ensure that data processing is efficient. Harmonized aggregates can be constructed from the DB, and key indicators according to the distinct categories can be calculated (Baldé, 2015).

Once collected, the total can be processed into indicators. The indicators developed shall provide an overview of the size of the local electronic market, collection and recovery volumes: Total EEE put on market $\left(\mathrm{kg} \mathrm{inh}^{-1}\right)$, Total WEEE generated $\left(\mathrm{kg} \mathrm{inh}^{-1}\right)$, WEEE Collected $\left(\mathrm{kg} \mathrm{inh}^{-1}\right)$, WEEE Collection Rate (\%) (Baldé, 2015). No data that can identify individual companies are to be published.

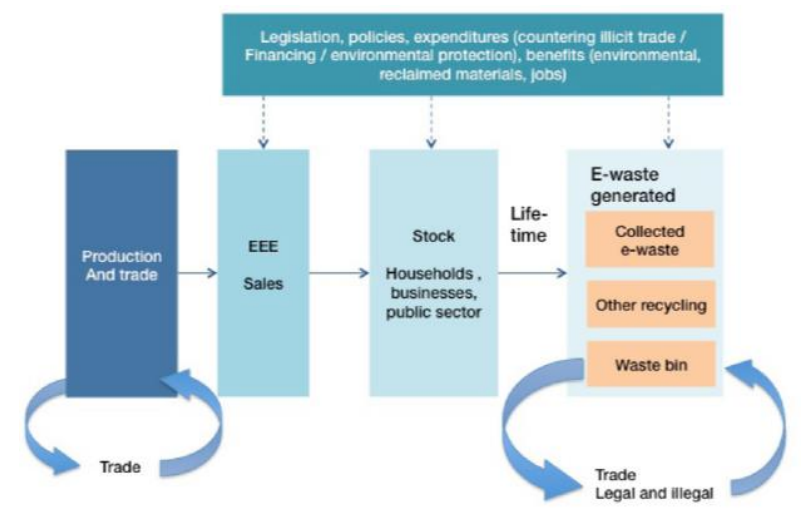

Figure 2. Measurement framework for WEEE flow Source: Baldé, 2015

\subsection{Conceptual model of a DBMS for WEEE}

A data model is a conceptual representation of the data structures. There are two major methodologies used to create a data model: The Entity-Relationship (ER) approach and the Object Model. The focus of this paper is the ER approach, often used in statistical DBMS. This model consists of a collection of basic objects, called entities, and of relationships among these objects (Taneja, 2017). A relational DB matches data using common characteristics, so that such data can be easily accessed (Halvorsen, 2016).

A basic component of the model is the ER diagram which is used to visually represent data objects (Taneja, 2017). The information of the requirements of the DBMS is transformed into a conceptual design stage connected with the analysis phase for the different requirements of information of WEEE.
Based on the requirements of the WEEE Directive (EU, $7 / 4 / 2012$ ), the authors are presenting a first conceptual DBMS for WEEE based on the ER approach (Taneja, 2017).

An initial ER diagram with entities and relationships containing the different information flows is developed in this paper (Figure 3). The goal is to provide a general structure of the DBMS, reaching a logical design level, indicating what attributes should be recorded in the database.

\subsubsection{Objectives of the WEEE DBMS}

Users of the DBMS are to provide data according to the WEEE Directive. These actors are categorized in the Directive as: producers, distributors, consumers, collectors, treatment plants, and refiners. Information of the running programs and projects, as well as from the legislators, shall be contained. Advanced users include administrators and designers, who shall develop the proposed conceptual model.

The goal is to provide access to all users regarding the following items: contents of EEE placed on the market, existence of hazardous materials, quantities of WEEE collected, location, composition, and WEEE material flows. Additional to this data, information regarding results on specific projects shall be shared among users to avoid duplication of knowledge and allowing a common poll. This information gathered from different actors will account for estimations of the target rates set by the EU Directive in every member state. Public reports shall be available to all users to verify the achievement of the different recycling quotas. The model of the DBMS is developed to fulfil these requisites

(Figure

$3)$.

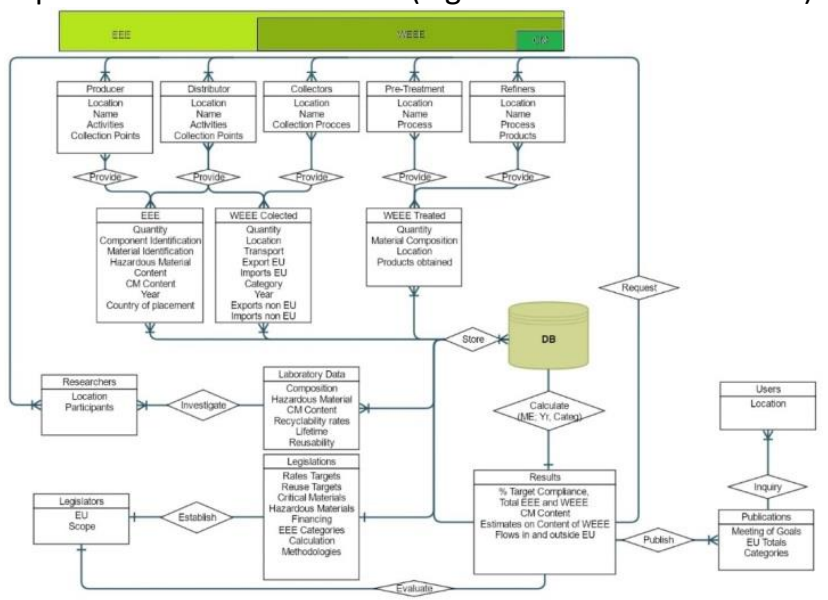

Figure 3. Conceptual design for data flow for a DBMS

\section{Survey on existing DB for WEE}

EEE producers that have chosen to deal with the WEEE Directive report to the national authorities, who report the data every two years to Eurostat, which provides access for its complete database (Eurostat, 2017). It contains data on waste generation and treatment, total waste, waste treated, total waste flows, imports and exports, and capacity of disposal facilities by country.

Within the waste DB, an overview of WEEE is presented for the EU and some European non-member countries 
according to the WEEE Directive. Data of EEE placed on the market and of WEEE collected and treated for the EU is presented. Missing data are estimated to show developments for the EU. Data of WEEE collected are presented by country in kg per inhabitant, and subdivided in ten categories of EEE covered by the EU Directive (Eurostat, 2016). Methodologies for estimations are not explained on the internet site.

ProdCom provides statistics annually on the domestic production and import/export volumes of manufactured goods for all European countries (Johnson and Fitzpatrick,
2016). Country specific EEE and WEEE data for France, Italy, the Netherlands and Belgium (Table 1) are already available from previous research conducted by the United Nations University (Huisman, 2014). This data show that there is already a development towards publishing statistics on these fields, but the data published contain only parts of the required field, and are presented heterogeneously, providing difficulties for its aggregation. There is no distinction between generated and collected waste, so the collection rates are not clearly presented.

Table 1. Survey on WEEE statistics in different member states

\begin{tabular}{cccccccccc}
\hline Country & $\begin{array}{c}\text { Producer } \\
\text { Registry }\end{array}$ & $\begin{array}{c}\text { Collector } \\
\text { Registry }\end{array}$ & $\begin{array}{c}\text { EEE } \\
\text { Placed }\end{array}$ & Stock & WEEE & $\begin{array}{c}\text { WEEE } \\
\text { Treated }\end{array}$ & $\begin{array}{c}\text { WEEE } \\
\text { Flows }\end{array}$ & $\begin{array}{c}\text { WEEE } \\
\text { Recycled }\end{array}$ & Format \\
\hline Denmark & Yes & No & Yes & Yes & Generated & Yes & No & No & PDF \\
\hline UK & No & No & Yes & No & Collected & Yes & No & No & XLSX \\
\hline Ireland & No & No & No & No & Collected & Yes & No & Yes & XLSX \\
\hline Netherlands & Yes & Yes & Yes & Yes & Generated & Yes & Yes & No & PDF \\
\hline Belgium & No & No & Yes & Yes & Generated & No & Yes & No & PDF \\
\hline Italy & No & No & Yes & Yes & Generated & No & No & No & PDF \\
\hline
\end{tabular}

Sources: Huisman, 2012; DPA, 2015; UK EA, 2017; EPA, 2013; Huisman and Baldé, 2013; Magalani, 2014

\section{Issues with WEEE data and practical solutions}

Given the various sources of data, the problem of heterogeneous disaggregated data appears as a challenge (Table 1). A solution to this is the implementation of a common standard for data transfer, so it can be easily processed. Data content of hazardous materials and CM contents is missing in every DB analysed in this paper, presenting difficulties to estimate these values since a harmonized methodology is lacking (Huisman, 2014). Estimations on the contents of CM can be done based on sample testing of WEEE, information is to be gathered by research institutions. Within the $\mathrm{EU}$, the key challenge of how to establish reliable information flows of WEEE and $\mathrm{CM}$ content remains. However, current data are quite unreliable and insufficient as the quality of the sources is not ensured since procedures are not in place to check the accuracy of these data sets.

As EEE producers and distributors place products on the markets, questions on the feasibility of the participation of such actors in the proposed DBMS arise. Due to the following reasons this paper assumes that such a participation is rather unlikely. First, the quantities of EEE products they put on the market is their key business and mainly profit driven. Second, the participation in the proposed DBMS may present additional administrative work. Third, there is a lack of product eco-design policy principles, such as extended/individual producer responsibility, and their current effective integration would rather raise questions on side of the producers as no economic incentives for a transition towards a more circular economic approach are given.

Hence, the following practical solutions are presented: a. Use End of Life (EOL) estimations to forecast WEEE stocks.

b. Use market models to estimate the quantity of EEE put on the market each year.

c. Estimate, based on laboratory results, contents of CM for different EEE and WEEE categories.

To achieve these solutions, the following is recommended:

\subsection{Strengthen research relationships between leading} WEEE research institutions

Within the EU, research institutions can support to extend this DB. Several existing EU projects focus on the recovery of CM such as REECOVER (Scandinavia), HydroWEEE (with partners from Italy) and BIOLOX (partners from Belgium). Such research shall be aligned and oriented on estimations of EOL, composition of WEEE, CM contained in WEEE, recycling mechanisms, recyclability of WEEE mixtures, economic feasibility of WEEE recycling and CM recovery. This would avoid duplication of results, coordinate actions of these projects, integrate state of the art research results at faster pace (such as tags in EEE products that estimate $\mathrm{CM}$ compositions). Furthermore, it would provide reliable results and conclusions of these projects, creating conditions so EEE producers investigate $\mathrm{CM}$ compositions in their products through eco-design and legislators include state policy making for the increased recovery of CM.

\subsection{Recyclers (pre-treatment and refinery companies)}

Recyclers may find some incentives since the information on existing WEEE is critical for their business. Reliable information of treated WEEE volumes and recovered CM rates can be crucial for incentivising its recovery, therefore feedback on this information is of high importance for a successful evaluation. 


\subsection{Reinforce EU member states local data gathering and collection schemes}

A cross country flow of information, such as in the case of Nordic countries, as examples of high collection rates and successful policies, can be useful to develop MS policies where recycling rates are not being achieved. The models of gathering and processing data shall be shared across the EU. Such information exchanges can facilitate the establishment of a DBMS. A minimum requirement of WEEE statistics is also proposed, which can be obtained via household surveys (Baldé, 2015).

\subsection{Implementation of the conceptual design on existing DBMS}

A standardized DBMS is convenient for future growth, facilitating expansion, development and integration with existing ones (Masood, 2017). The conceptual design presented in this paper could be used as framework for expansion and improvement of existing DBMS, such as Eurostat, which already present information on recovery and recycling rates EEE put on the market, collection and, Treatment of WEEE, by country, year and EEE-Category, in tonnes and kg per inhabitant, but lacks information on fields lie CM content or hazardous substances (Eurostat, 2017).

\section{Conclusions}

Knowledge on CM compositions in WEEE in the EU currently lacks reliable information for detailed analysis as the information is insufficient and disseminated through different stakeholders included in the EEE value chain. Hence, the authors proposed a conceptual design for a common DBMS, which incorporates different relevant actors that can help in gathering the principal information on the recovery of $\mathrm{CM}$ and follows the requirements of the EU Directive. The architecture of the proposed DBMS ensures an appropriate flow of information, availability for different actors, and clarity on the mechanism of processing this information, so that the target values set by the EU Directive can be properly monitored and are used as guidelines for further development.

After the proposed schema is compared to existing DBMS on WEEE, potential of implementation of this concept to expand the information flows was identified, so that the requirements of the EU Directive can be satisfied. However, it is difficult to modify existing DBMS configurations, especially if these are not standardized.

Therefore, the authors concluded that practical difficulties appear when considering the role of EEE producers and distributors, which can have access to relevant information on the CM compositions in their products and are unlikely to participate in the proposed DBMS without sufficient economic incentives in place. Furthermore, current data sets are insufficient, as they lack information on $\mathrm{CM}$ content, recoverability, and the methodologies for calculations are not clear, making their results uncertain. Heterogeneous unstructured data from different countries hinder aggregation and comparison between MS. These problems are also observed when considering existing DBMS, such as Eurostat.

Adequate information exchange, and completion of results were identified as key problems for the implementation of the proposed DBMS. It was therefore recommended that research institutions within the EU tighten their relationships to collectively produce relevant results for $\mathrm{CM}$ recovery methods that may lead to enhanced pressure on EEE producers and EU policy makers to help make the proposed DBMS feasible, and establish reliable information flows.

Future research should address the practicability of implementing the proposed conceptual schema of the DBMS, expanding existing DBMS, and on improving the quality of the data supplied by different actors.

\section{References}

Babu B., Parande A. and Basha C. (2007), Electrical and electronic waste: a global environmental problem. Waste Management \& Research, 25, 307-318.

Bakas I., Fischer C., Harding A. and Haselsteiner S. (2014), Present and Potential Future Recycling of Critical Metals in WEEE, Copenhagen Resource Institute, Copenhagen.

Balde C., Kuehr R., Blumenthal K., Fondeur Gill S., Kern M., Micheli P. and Huisman J. (2015), E-waste Statistics. Guidelines on Classification, Reporting and Indicators, Bonn, Germany.

Darbar G. and Suthar M. (2014), Study of the ANSI/SPARC Architecture.

DPA (2015), WEEE, BAT, and ELV Statistics 2014, DPA-System, Copenhagen.

EPA (2013), WEEE Statistics for Ireland in 2013. Environmental Protection Agency. Available online at http://www.epa.ie/ pubs/reports/waste/stats/weeedata2013/, accessed on 4/10/2017.

EU (7/4/2012a), Directive 2012/19/EU of the European Parliament and of the Council of 4 July 2012 on waste electrical and electronic equipment (WEEE), OJ 197.

European Commission (2017), Study on the Review of the List of Critical Raw Materials, Publications Office of the European Union, Brussels.

Eurostat (2017), Complete Database. Available online at http://ec.europa.eu/eurostat/data/database, accessed on 4/10/2017.

Halvorsen H. (2016), Introduction to Database Systems. Notodden, University College of Southeast Norway, Norway.

Harrison R. (1997), Database Systems Concepts. Available online at http://codex.cs.yale.edu/avi/db-book/db4/slide-dir/ch12.pdf, accessed on 4/10/2017.

Huisman J. (2014), Database and WEEE Classification Listing. Deliverable 2.3, United Nations University, Bonn.

Huisman J. and Baldé K. (2013), (W)EEE Mass Balance and Market Structure in Belgium, Brussels.

Huisman J., Magalini F., Kuehr R. and Maurer C. (2007), Review of Directive 2002/96 on Waste Electrical and Electronic Equipment, United Nations University, Bonn.

Huisman J., van der Maesen M., Eijsbouts R.J.J., Wang F., Baldé C.P. and Wielenga C.A. (2012), The Dutch WEEE Flows. 2011 Dutch e-Easte Quantification, United Nations University, Bonn. 
Johnson M. and Fitzpatrick C. (2016), The Development of a Model to Ascertain Future Levels of Historic WEEE Arising (Historic WEEE), Environmental Protection Agency, Wexford.

Magalani F. (2014), Household WEEE Generated in Italy. Analysis on Volumes \& Consumer Disposal Behaviour for Waste Electrical and Electronic Equipment, Bonn. Available online at http://www.weee-forum.org/system/files/2012_ecodom_ weee_arising_in_italy_en.pdf, accessed on 4/10/2017.

Marra A., Cesaro A. and Belgiorno V. (2018), Separation efficiency of valuable and critical metals in WEEE mechanical treatments. Journal of Cleaner Production, 186, 490-498.

Masood N. (2017), Database Management Systems. Pakistan.

OJEU (1993), Towards Sustainability. A European Community Programme of Policy and Action in Relation to the Environment and Sustainable Development, Official Journal of the European Communities, Brussels.

Puckett J., Byster L., Westervelt S., Gutierrez R., Davis S., Hussain A. and Dutta M. (2002), Exporting Harm, the High-tech Trashing of Asia. The Basel Action Network (BAN) and Silicon Valley Toxics Coalition (SVTC). Available online at http://www.ban.org/E-waste/technotrashfinalcomp.pdf, accessed on 4/05/2018.

Taneja A. (2017), Database Management Systems, 2017. Available online at http://www.ddegjust.ac.in/studymaterial /mca-3/ms-11.pdf, accessed on 4/10/2017.

UK Environment Agency (2017), Waste Electrical and Electronic Equipment (WEEE) in the UK. UK Environment Agency, London. Available online at https://www.gov.uk/ government/statistics/waste-electrical-and-electronicequipment-in-the-uk-2013, accessed on 4/10/2017.

Wei-Pang Y. (2017), Introduction to DBMS. Database Management Systems. National DongHwa University, 2017. Available online at http://opencourse.ndhu.edu.tw/ pluginfile.php/944/mod_resource/content/0/Advanced_Dat abase_Management_System/unit1.pdf, accessed on 4/10/2017. 